\title{
Oral supplementation of medium-chain fatty acids during the dry period supports the neutrophil viability of peripartum dairy cows
}

\author{
Sofie Piepers* and Sarne De Vliegher \\ M-team and Mastitis and Milk Quality Research Unit, Department of Reproduction, Obstetrics, and Herd Health, Faculty of Veterinary \\ Medicine, Ghent University, Merelbeke, Belgium
}

Received 23 July 2012; accepted for publication 19 February 2013

\begin{abstract}
A randomised clinical trial was conducted to explore the effect of orally supplemented medium-chain fatty acids (MCFA) to heifers and cows starting 6-8 weeks prior to expected calving date on blood and milk polymorphonuclear neutrophilic leucocyte (PMNL) apoptosis between 1 and $3 \mathrm{~d}$ in milk (DIM). The effects of MCFA-supplementation on the likelihood of intramammary infections (IMI) in early lactation, and test-day somatic cell count (SCC) and average daily milk yield (MY) during the first 4 months of lactation were evaluated as well. Twenty-two animals were included of which half were orally supplemented with MCFA starting 6-8 weeks prior to calving and half served as non-supplemented controls. The PMNL viability in both blood and milk was quantified using dual-colour flow cytometry with fluorescein-labelled annexin and propidium iodide. In non-supplemented animals, \% blood PMNL apoptosis significantly increased between start of supplementation and early lactation, reflecting a potential reduction in innate immune capacity, whereas this was not true in the MCFA-supplemented animals. Similar results were seen in milk PMNL apoptosis. Overall, the \% apoptotic milk PMNL between 1 and 3 DIM was significantly lower in the MCFA-supplemented group compared with the non-supplemented group. There was no substantial effect of oral MCFA-supplementation on the likelihood of quarter IMI nor on the composite test-day milk SCC or average daily MY. In conclusion, oral MCFA-supplementation starting 6-8 weeks before expected calving date supported the blood and milk neutrophil viability in early lactating dairy cows. Still, this was not reflected in an improvement of udder health nor MY in early and later lactation. The results should trigger research to further unravel the mechanisms behind the observed immunomodulating effect, and the potential relevance for the cows' performances throughout lactation.
\end{abstract}

Keywords: Apoptosis, dairy cow, medium-chain fatty acid, neutrophil.

The dry period is known as the most crucial yet ambivalent period for udder health in a cow's lactation cycle. The steady state involution phase offers an excellent opportunity for curing existing intramammary infections (IMI) whereas the active involution phase and colostrogenesis are conversely periods of high risk for contracting new IMI at the same time (Bradley \& Green, 2010). The incidence rate of IMI during the dry period is up to 10-times higher than the rate of IMI during lactation with a peak around involution of the mammary gland just after drying off and during the transition from pregnancy to lactation (Smith et al. 1985).

The high incidence of infectious diseases in early lactation in dairy cows such as clinical mastitis, has been directly

*For correspondence; e-mail: Sofie.Piepers@UGent.be linked to the impaired functionality of blood and milk polymorphonuclear neutrophilic leucocytes (PMNLs) at that time as compared with mid and late lactation (Mehrzad et al. 2001; Van Oostveldt et al. 2001, 2002). The pathways of this immunosuppression have yet not been fully unravelled although studies both in vitro and in vivo indicate that the oxidative stress cows undergo during transition is a major underlying factor (Bernabucci et al. 2005; Castillo et al. 2005; Sordillo \& Aitken, 2009). Stimulating or supporting the cellular immune function of periparturient dairy cows could potentially help them in meeting their challenges during this critical period around calving.

In human medicine, there is increasing evidence that medium-chain fatty acids (MCFA) have strong antioxidant properties, delaying or even preventing cell and tissue damage from oxidative stress (Henry et al. 2002; Lemieux et al. 2011). MCFA are naturally present in coconut oil, palm 
kernel oil and camphor tree drupes (Breckenridge \& Kuksis, 1967). Although a plethora of information is available on the immunomodulating effects of MCFA in humans (e.g. Bellinati-Pires et al. 1993; Wanten et al. 2002; Versleijen et al. 2005) only little is known about these effects in the bovine.

Hence the main objective of this study was to explore the effect of orally supplemented MCFA to heifers and cows starting 6-8 weeks prior to expected calving date on blood and milk PMNL functionality in early lactation. In addition, the effect of MCFA-supplementation on the likelihood of IMI in early lactation, and on the evolution of test-day somatic cell count (SCC) and milk yield (MY) during the first 4 months of lactation was evaluated. The findings could be helpful in generating new hypotheses on improving mammary gland immunity or udder health around calving through nutrition and give indications for future research.

\section{Materials and Methods}

The study was approved by the ethical committee of the Faculty of Veterinary Medicine, Ghent University (EC 2008/ 137).

\section{Herd}

A randomised blind clinical trial was conducted from June 2009 to June 2010 on the research dairy farm of Ghent University (Biocentrum Agri-Vet, Melle, Belgium) equipped with a free-stall barn with saw-dusted cubicles and a Voluntary Milking System (VMS, DeLaval, Tumba, Sweden). The herd consisted of approximately 50 lactating Black Holstein-Friesian cows at the time the trial was conducted. Mean 305-d production was $9565 \mathrm{~kg}$. Average bulk milk SCC during the study period was 266000 cells $/ \mathrm{ml}$. Both pregnant heifers and dry cows had access to pasture between June and October, and were kept indoors between October and June. In the period the heifers were kept indoors, they were fed grass silage, corn silage and hay. Additionally, $150 \mathrm{~g} / \mathrm{d}$ of a commercial mineral/vitamin mix containing vitamin $\mathrm{E}$, Se, magnesium, zinc and copper was fed (Prolacta ${ }^{\circledR}$, AVEVE, Belgium). Dry cows were daily fed $25 \mathrm{~kg}$ of corn silage, $0.5 \mathrm{~kg}$ of protein supplements, hay ad libitum and $200 \mathrm{~g}$ of a commercial dry cow mineral/vitamin mix containing vitamin $\mathrm{E}$, Se, magnesium, zinc and copper (Prolacta $^{\circledR}$, AVEVE, Belgium). At dry-off, broad-spectrum long-acting antibiotics were introduced in each quarter [Virbactan (ex. Cobactan D.C.), VIRBAC Animal Health, Leuven, Belgium]. Both heifers and cows were introduced to the group of lactating cows approximately 2 weeks before expected calving date. A couple of days before calving, the animals were moved to box stalls bedded with straw.

\section{Study design}

On the farm, a cohort of twelve conveniently selected (i.e. based on the expected calving date) end-term second lactation cows and 10 end-term heifers were blocked by parity, alternately assigned to either the control $(n=11)$ or the MCFA (supplemented) group $(n=11)$ at dry-off and $45 \mathrm{~d}$ before the expected calving date, respectively. All animals were clinically healthy at the moment of inclusion. Heifers and cows with general signs of disease or with signs of clinical mastitis [any abnormal aspect of the milk (flakes, clots, and a watery or other unusual appearance) whether or not in combination with other visible abnormalities of the udder (redness, swelling, ...)] between selection and calving were excluded from the study and replaced by the animal within the same parity block that was closest to dry-off. One cow belonging to the MCFA-supplemented group was excluded and replaced for this reason because she suffered from a severe case of clinical mastitis $5 \mathrm{~d}$ before calving. Both the control and supplemented group eventually consisted of 5 heifers and 6 multiparous cows. A trial period for an individual animal lasted approximately 160-190 d, encompassing either the entire dry period (average $52 \mathrm{~d}$ ) for multiparous cows or 38-66 d before calving (average $53 \mathrm{~d}$ ) for heifers, and the first 4 months of the subsequent lactation. Daily oral supplementation of $25 \mathrm{~g}$ of a mix of MCFA (concentration active substance $500 \mathrm{mg} / \mathrm{g}$ ) (Aromabiotic Cattle ${ }^{\circledR}$, Nuscience, Drongen) per animal started at dry-off for multiparous cows and 7 weeks prior to expected calving date for end-term heifers and continued up to 4 months in lactation. The dose was chosen based on the manufacturers' prescriptions. All animals calved between September 2009 and March 2010.

\section{Sample collection}

Blood samples. Six to eight weeks before expected calving date and between 1 and 3 DIM (referred to as early lactation throughout the paper), blood samples $(30 \mathrm{ml})$ were collected from the tail vein using EDTA vacutainer tubes (Terumo, Leuven, Belgium) to determine blood PMNL viability of all 22 animals. After collection, the blood samples were mixed with $30 \mathrm{ml}$ Alsever's solution as anticoagulant in a $60-\mathrm{ml}$ syringe for further processing.

Milk samples. Milk samples were obtained from the multiparous cows at dry-off and early lactation (colostral phase), and in early lactation only for the heifers at the same time of blood sampling. Firstly, duplicate quarter milk samples for bacteriological culturing were aseptically collected before milking after the first three streams of milk were discarded. Subsequently, single quarter milk samples were collected for determination of the milk PMNL viability $(100 \mathrm{ml})$ and somatic cell count (SCC) $(30 \mathrm{ml})$. Twenty-five $\mathrm{ml}$ and $10 \mathrm{ml}$ milk of each quarter was transferred into one tube in order to obtain a composite milk sample for determination of the PMNL viability and SCC, respectively. 


\section{Intramammary infection status}

Bacteriological culturing. The intramammary infection status was determined based on bacteriological culturing. Bacteriological culturing and isolate identification of milk was done as previously described (Piepers et al. 2007). A milk sample was considered culture-positive when growth of $\geqslant 4$ colonies was detected, except for quarters infected with Staphylococcus aureus or Streptococcus agalactiae which were considered as culture-positive when growth of $\geqslant 1$ colony was detected. Samples yielding colonies of $\geqslant 3$ different bacterial species were considered to be contaminated. The plates were incubated aerobically at $37^{\circ} \mathrm{C}$ and examined at 24 and $48 \mathrm{~h}$.

Definition of intramammary infection status. The IMI-status was defined at the quarter level as previously described by Pantoja et al. (2009). A quarter was considered infected when the same mastitis pathogen was isolated from both duplicate milk samples. Isolation of a mastitis pathogen from only one of the duplicate milk samples was considered non-significant growth classifying a quarter as non-infected. When one of the duplicate samples was contaminated but no organisms were recovered from the other sample the quarter was considered to be non-infected. When both duplicate milk samples were contaminated the data were considered missing.

\section{Blood and milk neutrophil apoptosis}

Isolation and identification of blood and milk neutrophils. Blood and milk PMNL were isolated and identified as described by Piepers et al. (2009a). Briefly, isolation of blood leucocytes was performed by centrifugation (300 g), removal of plasma and buffy coat, hypotonic lysis of erythrocytes, and two washing steps (Mehrzad et al. 2002). The final volume of composite milk $(100 \mathrm{ml})$ was divided equally over four 50-ml Falcon tubes, diluted 50\% vol/vol with cold phosphate-buffered saline (PBS), and centrifuged (300 g) at $4{ }^{\circ} \mathrm{C}$ for $15 \mathrm{~min}$ (Piepers et al. 2009a). After carefully removing the cream layer, the pellet was resuspended, centrifuged, and washed two more times (Mehrzad et al. 2002).

Blood PMNL were discriminated from other blood cells based on their size and internal complexity in a forward-side scatter dot plot (FSC-SSC dot-plot) (Van Oostveldt et al. 2001). For milk, a two-step fluorescent immunolabelling using a primary anti-bovine monoclonal granulocyte antibody (CH138A) (VMRD Inc., Pullman WA, USA) and an Alexa 647-labelled goat anti-mouse IgM secondary antibody (Molecular Probes, Leiden, The Netherlands) was conducted (Piepers et al. 2009a). Milk PMNL were differentiated from other milk cells based on their cytoplasmatic granularity and mean fluorescence intensity. Cell debris was gated out setting an optimised threshold of 10000 based on the forwardscatter properties in the FSC-SSC dot-plot. Milk PMNL were eventually identified using the SSC vs. Alexa 647 dot-plot by drawing a gating region to enclose the PMNL based on the cytoplasmic granularity and $\mathrm{CH} 138 \mathrm{~A}$ positivity as previously described (Piepers et al. 2009a). Recordings of scatter and fluorescent properties were performed on 10000 gated events. Results were corrected for autofluorescence which was defined as the fluorescence associated with nonlabelled freshly isolated milk PMNL of the same cow.

Quantification of blood and milk neutrophil apoptosis. Apoptotic PMNL were identified using a double fluorescent isothiocyanate (FITC)-annexin- $\mathrm{V}$ and propidium iodide (PI) staining (Van Oostveldt et al. 2001; Piepers et al. 2009a). As apoptosis does not occur in circulation (Van Oostveldt et al. 1999a) spontaneous apoptosis in blood was induced by incubating the isolated blood PMNL for $18 \mathrm{~h}$ at $37^{\circ} \mathrm{C}$ before PMNL viability was determined. PMNLs that were positive for FITC and negative for PI were considered as (early) apoptotic, whereas PMNL that were positive for both FITC and PI were considered as necrotic (Vermes et al. 1995; Van Oostveldt et al. 2001; Piepers et al. 2009a). PMNLs that were negative for both FITC and PI were considered as viable. Both the viable and necrotic subpopulation was excluded from the analysis. All analyses were performed on a double-laser, bench-top flow cytometer (BD FacsCanto II) and processed using FACSDiva Software (Becton Dickinson, Belgium). The data were described as mean \pm SEM. For the statistical analysis, a square-root transformation of the $\%$ of apoptotic blood and milk PMNL was used to normalise the data.

\section{Test-day somatic cell count and milk yield}

Composite milk SCC and MY (kg milk/d) at test-day for the first 4 recordings (on average up till 137 DIM) were available per animal on a four-weekly basis as part of the $\mathrm{DHI}$ programme. Milk SCC was quantified by electronic counting (Fossomatc 5000 ${ }^{\mathrm{TM}}$, Foss Electric, Hillerød, Denmark) at the Milk Control Centre, Flanders (Lier, Belgium). The data were described as mean \pm SEM. For the statistical analysis, a natural logarithmic transformation of the test-day SCC (LnSCC) was performed to obtain a normal distribution.

\section{Statistical analyses}

Prior to statistical analysis, all observations were explored and checked for unlikely values. No data were excluded for this reason. A square-root transformation of the \% apoptotic PMNL (both blood and milk) and a natural logarithmic transformation of SCC (LnSCC) were performed to normalise the data.

Several (mixed) regression models (1) to (4) were fitted to determine the association between the supplementation status of the animals (supplemented vs. non-supplemented control) and the \% PMNL apoptosis, the likelihood of IMI in early lactation and the test-day SCC and MY during the first 4 months of lactation, respectively, using SAS 9.3 
(SAS Institute Inc., Cary NC, USA) unless otherwise mentioned.

$\mathbf{Y}_{i j}=\beta_{0}+\beta_{1} \operatorname{Supp}+\beta_{2} \operatorname{Per}+\beta_{3} \operatorname{Par}+\boldsymbol{\mu}_{\operatorname{Cow}(j)}+\mathbf{e}_{i j}$,

where $Y$ is the observed value for either the \% apoptotic blood or milk PMNL and where $\boldsymbol{\mu}_{\text {Cow (j) }}$ is the repeated effect of the cow $i$ ( $i=1$ to 22 ) containing the $j$ th observation ( $j=1$ or 2 ), and $\mathbf{e}_{i j}$ is the random error term;

$\mathbf{Y}_{i}=\beta_{0}+\beta_{1}$ Supp $+\beta_{2}$ Par

with $Y$ being the observed value for the \% apoptotic milk PMNL in early lactation (1-3 DIM) of cow $i$ ( $i=1$ to 22$)$. This model was fitted in MLwiN 2.02 (Centre for Multilevel Modelling, Bristol, UK);

$\mathbf{Y}_{i j}=\beta_{0}+\beta_{1}$ Supp $+\beta_{2}$ Test $+\beta_{3}$ Par $+\boldsymbol{\mu}_{\operatorname{Cow}(\mathrm{j})}+\mathbf{e}_{i j}$,

where $Y$ is the observed value for the test-day SCC and MY at the $j$ th observation, respectively, and where $\boldsymbol{\mu}_{\text {Cow(j) }}$ is the repeated effect of the cow $i(i=1-22)$ containing the $j$ th observation $(j=1-4)$, and $\mathbf{e}_{i j}$ is the random error term;

$\operatorname{Logit}\left(\mathbf{Y}_{i j}\right)=\beta_{0}+\beta_{1} \operatorname{Supp}+\beta_{2} \operatorname{Par}+\boldsymbol{\mu}_{\operatorname{Cow}(j)}+\mathbf{e}_{i j}$,

where $Y_{i j}$ is the probability of the $j$ th quarter within the ith animal having IMI in early lactation ( 1 and 3 DIM), and $\mathbf{e}_{i j}$ is the random error term. This model was fitted in MLwiN 2.02 (Centre for Multilevel Modelling, Bristol, UK).

In all models, $\boldsymbol{\beta}_{0}$ is the intercept (overall mean), $\boldsymbol{\beta}_{1}$ to $\boldsymbol{\beta}_{3}$ are the regression coefficients of the different fixed effects included as categorical predictor variables $[\mathbf{S u p p}=$ the fixed effect of the MCFA-supplementation status of the animals (two levels; supplementation vs. no supplementation), Per=the fixed effect of the period in which the observation was obtained (two levels; at dry-off vs. early lactation), Test $=$ the fixed effect of test-day (five levels; 15-45 DIM, 46-75 DIM, 76-125 DIM, 126-155 DIM, 156-185 DIM) at which the SCC and MY were determined, and $\mathbf{P a r}=$ the fixed effect of the parity of the animals (two levels; heifers vs. multiparous cows)]. The model with the outcome variable test-day MY was further adjusted for LnSCC at test-day by including it as an additional predictor variable. In the mixed regression models (1) and (3), compound symmetry covariance structures were used to model the autocorrelation in the residual error in the repeated measures of the response variables. The goodness of fit measures for the mixed regression models included -2 loglikelihood (-2LL), Akaike's information criterion (AIC), and Bayesian information criterion (BIC). Significance was assessed at $P \leqslant 0 \cdot 05$. A backwards stepwise reduction was performed to obtain the final model. In all models, all first-order interactions were tested and removed when non-significant $(P>0 \cdot 05)$.

\section{Results}

Intramammary infection in early lactation

In general, $31 \cdot 2 \%$ of the quarters were infected at dry-off. Coagulase-negative staphylococci (CNS) and Corynebacterium bovis accounted for 73.3 and $26 \cdot 7 \%$ of the infections, respectively. None of the quarters was infected with Staphylococcus aureus, Streptococcus uberis, Streptococcus agalactiae, Streptococcus dysgalactiae or Gram-negative bacteria. In early lactation $20 \cdot 5 \%(n=70)$ of all quarters was infected with CNS accounting for $83.3 \%$ $(n=15)$. Staph. aureus and Str. uberis were isolated from one and two quarters, respectively. Odds of IMI (all pathogens) among animals in early lactation was not significantly different between multiparous cows and heifers (OR: $0 \cdot 2 ; 95 \% \mathrm{Cl}$ $0 \cdot 04,1 \cdot 3)$.

The effect of MCFA-supplementation starting at dry-off on the likelihood of IMI was evaluated on 48 duplicate quarter milk samples collected from multiparous cows at dry-off and on 88 duplicate quarter milk samples collected from both heifers and multiparous cows in early lactation. Odds of IMI (all pathogens) among animals in early lactation was not significantly different between supplemented and nonsupplemented animals (OR: $2 \cdot 15 ; 95 \% \mathrm{Cl}: 0 \cdot 4,12 \cdot 8)$. During the first month of lactation, 2 control animals contracted each one case of clinical mastitis.

\section{Blood and milk neutrophil apoptosis}

Blood neutrophil apoptosis. The \% apoptotic blood PMNL at $6-8$ weeks before calving was $14 \cdot 1 \pm 1 \cdot 5 \%$ (range $4 \cdot 4-37 \cdot 1 \%$ ) and increased to $26 \cdot 4 \pm 2 \cdot 6 \%$ (range $7 \cdot 7-45 \cdot 3 \%$ ) in early lactation. The \% apoptotic blood PMNL was significantly higher in multiparous cows $(22 \cdot 9 \pm 3 \cdot 1 \%)$ compared with heifers $(17 \cdot 1 \pm 3 \cdot 7 \%)(P<0 \cdot 05)$. At the beginning of supplementation, \% blood PMNL apoptosis was not different between the control and supplemented animals (Fig. 1). Blood PMNL apoptosis in the control group increased from $13 \cdot 1 \pm 1 \cdot 4 \%$ at dry-off to $33 \cdot 1 \pm 3 \cdot 5 \%$ in early lactation (Fig. 1). Control animals had a significantly higher \% blood PMNL apoptosis in early lactation (33.1 $\pm 3 \cdot 5 \%$ ) than supplemented animals (19.7 $\pm 2 \cdot 4 \%$ ) (Fig. 1). In the supplemented animals, \% apoptotic blood PMNL remained more or less stable between start of supplementation $(15 \cdot 2 \pm 2 \cdot 7 \%)$ and early lactation $(19 \cdot 7 \pm 2 \cdot 4 \%$ ) (Fig. 1 ).

Milk neutrophil apoptosis. Post-partum milk PMNL apoptosis was more pronounced in multiparous cows $(49 \cdot 8 \pm 5 \cdot 3 \%)$ than in heifers $(34 \cdot 4 \pm 3 \cdot 4 \%)(P<0 \cdot 01)$. No association was found between the quarter IMI-status and milk PMNL apoptosis. At dry-off, milk PMNL apoptosis in multiparous cows did not differ between the control $(43 \cdot 1 \pm 4 \cdot 0 \%)$ and MCFA supplemented group $(37 \cdot 7 \pm 4 \cdot 2 \%)$. Still, in control animals \% apoptotic milk PMNL increased throughout the dry period from $43 \cdot 1 \pm 4 \cdot 0 \%$ at dry-off to $61 \cdot 5 \pm 5 \cdot 4 \%$ in early lactation whereas in supplemented animals milk PMNL 


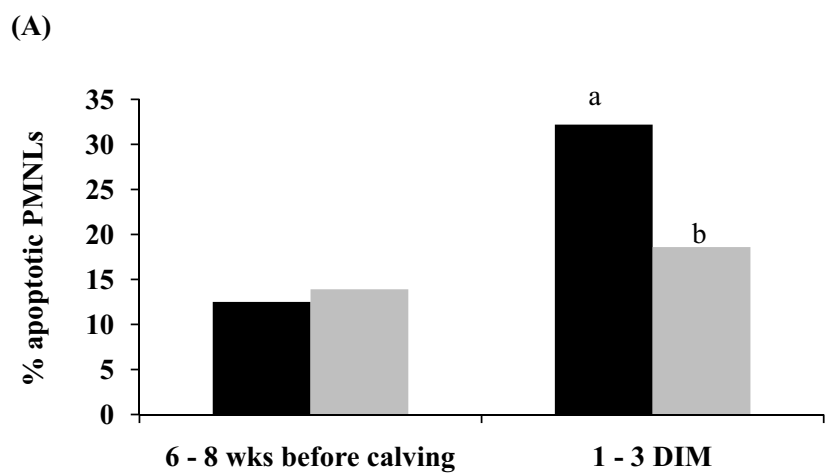

(B)

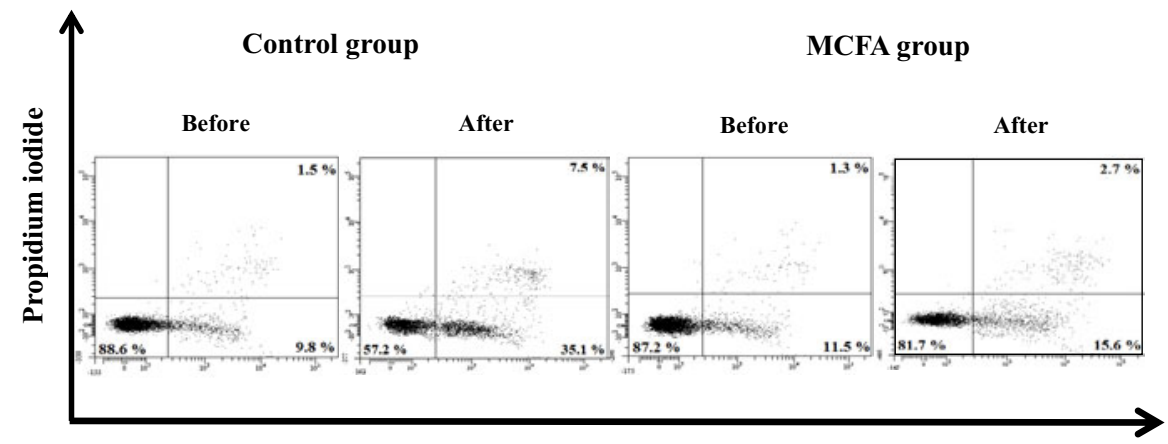

Annexine-V-FITC

Fig. 1. (a) Back-transformed least square means of \% apoptotic blood polymorphonuclear neutrophilic leucocytes (PMNLs) in both control $(\square)$ and MCFA-supplemented $(\square)$ animals between the start of supplementation (6-8 weeks before expected calving date) and early lactation [1-3 d in milk (DIM)]. Significant pairwise differences $(P<0 \cdot 05)$ within and between treatment groups are indicated by a and $b$, respectively. In control animals, \% apoptotic blood PMNLs (5 heifers and 6 multiparous cows) was significantly higher in early lactation than at dry-off. Control animals had a significantly higher \% apoptotic blood in early lactation compared to the MCFA-supplemented animals (5 heifers and 6 multiparous cows). (B) Representative flow cytometric analysis of blood PMNLs with a dual colour Annexin-V-fluorescein (FITC) and propidium iodide staining in control and MCFA-supplemented animals between the start of supplementation (6-8 weeks before expected calving date) and early lactation [1-3 d in milk (DIM)]. The percentage of negative (=viable), single positive (apoptotic) and double positive (=necrotic) PMNLs is shown in the individual quadrants.

apoptosis remained stable throughout the dry period (from $37 \cdot 7 \pm 4 \cdot 2 \%$ to $38 \cdot 0 \pm 4 \cdot 3 \%$ ) (Fig. 2). Milk PMNL apoptosis in early lactation was higher in non-supplemented $(51 \cdot 6 \pm 4 \cdot 9 \%)$ than in MCFA-supplemented animals $(33.9 \pm 3 \cdot 1 \%)$ in both heifers and multiparous cows $(P<0 \cdot 001)$ (Fig. 3$)$.

\section{Test-day somatic cell count and milk yield}

Test-day SCC decreased from $419091 \pm 84633$ cells $/ \mathrm{ml}$ in early lactation ( 1 and 3 DIM) to $125636 \pm 68792 \mathrm{cells} / \mathrm{ml}$ at first test-day and then again gradually increased to $241045 \pm 109753 \mathrm{cells} / \mathrm{ml}$ at the 4 th test-day. Multiparous cows had higher test-day SCC compared with heifers and the increase in test-day SCC over time was more pronounced in multiparous cows than in heifers ( $P$-value for parity $\times$ DIM <0.05) (Fig. 4).

Average daily MY increased from $37 \cdot 4 \pm 1 \cdot 5 \mathrm{~kg} / \mathrm{d}$ at first test-day to $40 \cdot 7 \pm 1.6 \mathrm{~kg} / \mathrm{d}$ at second test-day and then gradually decreased to $37 \cdot 5 \pm 1 \cdot 1 \mathrm{~kg} / \mathrm{d}$ at last test-day of the trial. Multiparous cows started at a much higher daily MY than heifers, but the increase in daily MY to peak production at first test-day was less pronounced (Fig. 5). Test-day LnSCC was negatively associated with the average daily MY at test-day.

Supplementation was not associated with test-day SCC $(P=0.34)$ although a slightly higher test-day SCC was observed in the MCFA-supplemented multiparous cows compared with the non-supplemented multiparous cows, in particular at 2 months after calving $(P=0 \cdot 14$; Fig. 4). No overall effect of MCFA-supplementation on average daily MY was observed $(P=0.45)$ although a tendency for a higher average daily $\mathrm{MY}$ at second test-day was seen in multiparous cows ( $P=0 \cdot 06$; Fig. 5).

\section{Discussion}

The work reported here was set out to explore the effect of oral supplementation of a commercially available mix of 
(A)

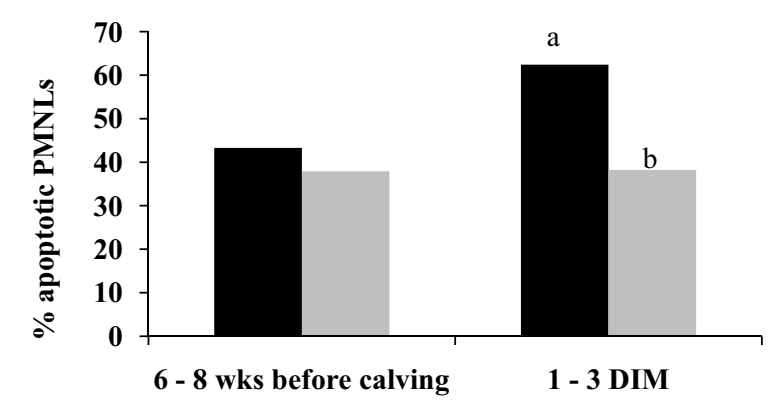

(B)

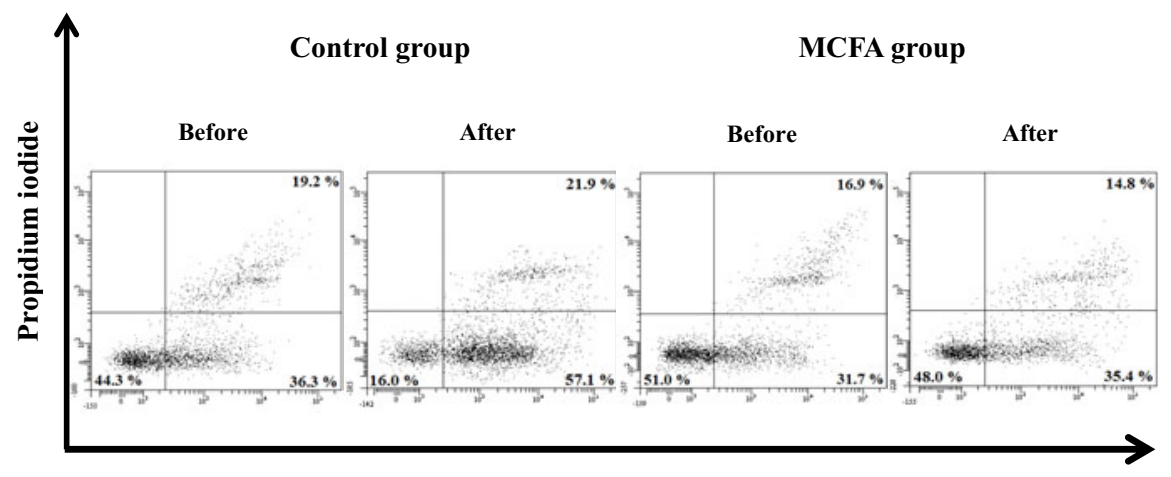

Annexine-V-FITC

Fig. 2. (a) Back-transformed least square means of \% apoptotic milk polymorphonuclear neutrophilic milk leucocytes (PMNLs) in both control ( $\square$ ) and MCFA-supplemented $(\square)$ animals between the start of supplementation (6-8 weeks before expected calving date) and early lactation [1-3 d in milk (DIM)]. Significant pairwise differences $(P<0 \cdot 05)$ within and between treatment groups are indicated by a and $b$, respectively. In control animals, \% apoptotic milk PMNLs (6 multiparous cows) was significantly higher in early lactation than at dry-off. Control animals had a significantly higher\% apoptotic milk PMNLs (6 multiparous cows) in early lactation compared to the MCFAsupplemented animals (6 multiparous cows). (b) Representative flow cytometric analysis of milk PMNLs with a dual colour AnnexinV-fluorescein (FITC) and propidium iodide staining in control and MCFA-supplemented animals between the start of supplementation (6-8 weeks before expected calving date) and early lactation [1-3 d in milk (DIM)]. The percentage of negative (=viable), single positive (apoptotic) and double positive (=necrotic) PMNLs is shown in the individual quadrants.

MCFA to heifers and multiparous cows starting at 6-8 weeks prior to calving on PMNL apoptosis and udder health in early lactation as well as on udder health and MY in the first months of lactation in a small-scale, randomised blind clinical trial. Neutrophil apoptosis was determined both in blood and milk using an innovative and accurate flow cytometric method (Piepers et al. 2009a). Animals in supplemented and control groups did not differ significantly in $\%$ blood and milk PMNL apoptosis at the time of enrolment. However, in early lactation, substantial differences in both blood and milk PMNL apoptosis were observed. In contrast to similar trials in which the effect of other nutrients was evaluated (Ceballos et al. 2009; Bouwstra et al. 2010), supplementation was carried out at the individual cow level rather than at the herd or a group level thereby avoiding the introduction of ecological fallacy (Schukken et al. 1988). This allowed us to precisely picture the relationship between oral supplementation of MCFA and the blood and milk
PMNL viability over the dry period. Although interesting statistically significant associations between MCFA supplementation and both blood and milk PMNL apoptosis were found, this obviously does not prove causality and basically needs confirmation. Rather, the findings generate new hypotheses on improving mammary gland immunity or udder health around calving through nutrition and give indications for future research.

MCFA are composed of six $\left(\mathrm{C}_{6} \mathrm{H}_{12} \mathrm{O}_{2}\right.$, caproic acid), eight $\left(\mathrm{C}_{8} \mathrm{H}_{16} \mathrm{O}_{2}\right.$, caprylic acid), ten $\left(\mathrm{C}_{10} \mathrm{H}_{20} \mathrm{O}_{2}\right.$, capric acid), twelve $\left(\mathrm{C}_{12} \mathrm{H}_{24} \mathrm{O}_{2}\right.$, lauric acid) or fourteen $\left(\mathrm{C}_{14} \mathrm{H}_{28} \mathrm{O}_{2}\right.$, myristic) carbons and are derived from medium-chain triglycerides which are well-known therapeutic fatty acids in human medicine for the treatment of patients suffering from malabsorption or malnutrition. MCFA passively diffuse from the intestines to the hepatic portal vein without requiring any modification like long-chain fatty acids or very-long-chain fatty acids and thus no energy is needed for absorption, 


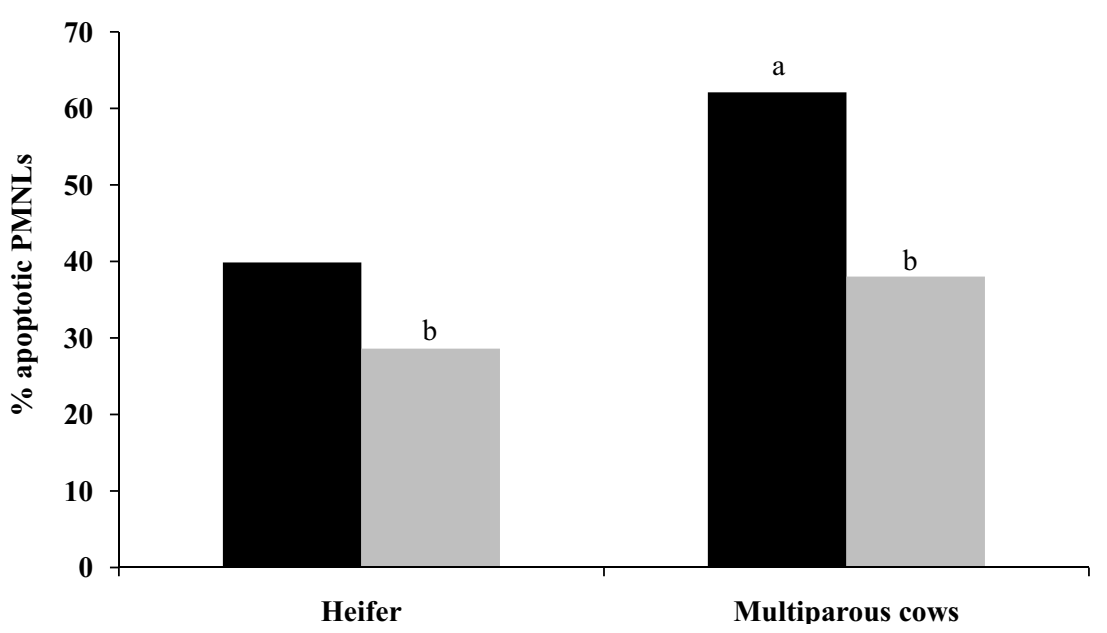

Fig. 3. Back-transformed least square means of \% apoptotic polymorphonuclear neutrophilic milk leucocytes (milk PMNLs) in both control $(\mathbb{\square})$ and MCFA-supplemented $(\square)$ animals in early lactation [1-3 d in milk (DIM)] for heifers and multiparous cows. Significant pairwise differences $(P<0.05)$ within and between treatment groups are indicated by a and b, respectively. Control animals $(5$ heifers and 6 multiparous cows) had a significantly higher \% apoptotic milk PMNLs in early lactation compared to the MCFA-supplemented animals (5 heifers and 6 multiparous cows), independently from their parity.

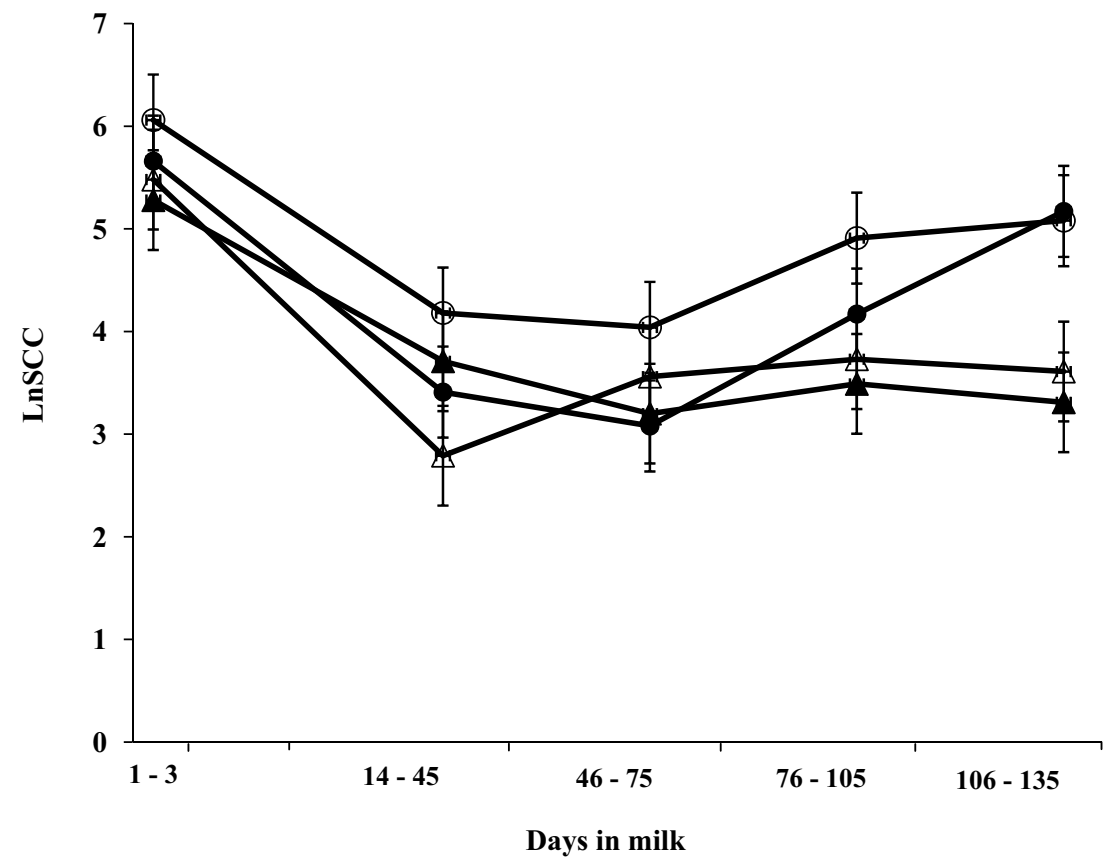

Fig. 4. Least square means ( \pm SEM) of the natural logarithmic transformed composite somatic cell count (LnSCC) during the first 4 months of lactation of medium-chain fatty acids (MCFA)-supplemented multiparous cows (O), non-supplemented multiparous cows ( $)$ ), MCFAsupplemented heifers $(\triangle)$ and non-supplemented heifers $(\mathbf{A})$. Multiparous cows had a significantly higher LnSCC than heifers. No significant differences were observed between MCFA-supplemented animals and control animals.

utilisation or storage (Bach \& Barbayan, 1982). In cattle, MCFA are particular renowned for their antimicrobial activity against the rumenal microflora, influencing the rumenal fermentation and thereby reducing the emission of greenhouse gases such as methane which are partly involved in the global warming process (Dohme et al. 2000, 2001). Caprylic acid possessed a bactericidal effect in vitro against major mastitis pathogens (Nair et al. 2005). Besides the microbicidal activity, there is in humans increasing evidence that MCFA have immunomodulating activities (Bellinati-Pires et al. 1993; Wanten et al. 2002; Versleijen et al. 2005).

Apoptosis of bovine PMNL implies an impaired phagocytotic and oxidative burst activity (Van Oostveldt et al. 


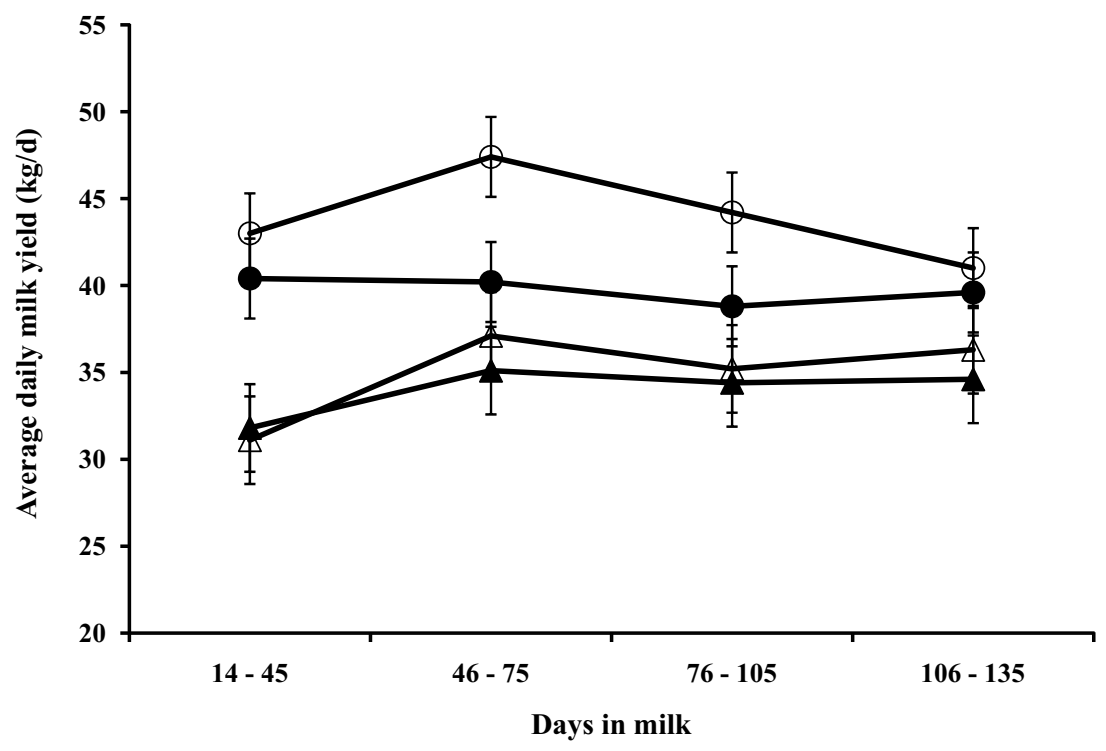

Fig. 5. Least square means $( \pm$ SEM) of the average daily milk yield $(M Y)$ during the first 4 months of lactation of medium-chain fatty acids (MCFA)-supplemented multiparous cows $(O)$, non-supplemented multiparous cows $(\bullet), M C F A$-supplemented heifers $(\triangle)$ and nonsupplemented heifers $(\mathbf{\Delta})$. Test-day MY was significantly higher in multiparous cows than in heifers. Overall, no significant differences in test-day MY were observed between MCFA-supplemented and control animals, although test-day MY at second test-day tended to be higher in supplemented multiparous cows than in their non-supplemented counterparts $(P=0 \cdot 06)$.

2002; Mehrzad et al. 2004) and has been associated with a less proper host response to IMI (Mehrzad et al. 2004, 2005). Determining the PMNL phagocytotic and oxidative burst capacity itself might have given the results more strength. Still, based on the findings of the above-mentioned studies in which a very close relationship was observed between PMNL apoptosis and oxidative burst activity, we were confident that measuring PMNL apoptosis would allow us to get a decent first indication of what potentially can be expected from the oral supplementation of MCFA on the innate immunity of dairy cows in early lactation.

Analogous to previous studies (Mehrzad et al. 2002; Piepers et al. 2009b), PMNL apoptosis was much more pronounced in milk than in blood. The latter finding can be explained by the diapedesis of blood PMNL through the blood-milk barrier and the ingestion of milk proteins and fat globules once the PMNL have migrated into the mammary gland. Both diapedesis through the blood-milk barrier and ingestion of milk proteins and fat globules are known to induce PMNL apoptosis (Van Oostveldt et al. 1999b; Paape et al. 2003). Similar to the findings of Mehrzad et al. (2002) a higher \% apoptotic blood and milk PMNL was observed in multiparous compared with primiparous cows. Decreased PMNL viability and functionality around calving, as was observed in the control animals in the present study, has been thoroughly documented in literature as well (Guidry et al. 1976; Kehrli et al. 1989; Van Oostveldt et al. 2001).

Cows that were orally supplemented with MCFA appeared to be protected against the drop in both blood and milk PMNL viability during periparturient period as evidenced by the stable \% PMNL apoptosis in both blood and milk when comparing start of supplementation and early lactation. In non-supplemented controls, \% blood PMNL apoptosis significantly increased between start of supplementation and the first days after calving whereas no substantial change in \% blood PMNL apoptosis could be observed in the supplemented animals. Additionally, \% apoptotic milk PMNL in early lactation was lower in supplemented animals compared with control animals, independently of their parity. The mechanisms by which MCFA could exert these potential immunomodulating effects are yet not unravelled and are basically beyond the scope of this study. Still, as this study is in essence a hypotheses generating study, some hypotheses, primarily derived from findings in human medicine literature, that might give perspectives for future research are put forward. First, MCFA might involve a reduction of the negative effects of oxidative-stressed cows during transition. Oxidative stress is the result of an imbalance between increased production of reactive oxygen species (ROS) causing cell and tissue damage and reduced availability of antioxidants usually protecting cells from the damaging effects of ROS. We previously found that supplementing heifers with a commercial mineral/vitamin mix before calving was associated with less blood and milk PMNL apoptosis in early lactation. The latter finding was presumably related to higher concentrations of blood Se, a well-known anti-oxidant (Piepers et al. 2009b). In rats and humans, MCFA such as lauric acid seems to be able to scavenge free radicals and thus are most likely to delay or even prevent cell/tissue damage from oxidative stress (Henry et al. 2002; Lemieux et al. 2011). Given the structure of MCFA including a hydroxyl group MCFA could act as 
peroxyl radical scavengers in a similar way to vitamin $\mathrm{E}$ by reacting with those radicals and by transferring themselves into a MCFA-radical (MCFA-O ${ }^{-}$) which could subsequently be oxidised by a hydrogen donor such as vitamin C. Also, as MCFA are fat-soluble and less prone to oxidation compared with the poly-unsaturated fatty acids, they can be incorporated into cell membranes in similarity with humans, protecting them again from oxidative damage (Lemieux et al. 2008). The effect of MCFA on the PMNL viability and activity might also be mediated by G-protein coupled receptors (Versleijen et al. 2009). G-proteins are a family of signal transducing proteins involved in transmitting chemical signals outside the cell and causing changes inside the cell. Some of those G-proteins are abundantly expressed in human monocytes and PMNL and were shown to have MCFA as ligands. Whether or not this kind of G-proteins are expressed on the surface of bovine PMNL has yet not been investigated and gives perspectives for further research. Clearly, these are just some hypotheses derived from findings in humans and rats; much more study is required to confirm and elucidate the potential immunomodulating effects of MCFA on PMNL viability in bovine and the underlying mechanisms behind those effects.

Higher blood and milk PMNL viability is expected to result in a more proper host response to IMI (Mehrzad et al. 2004). Consequently, fewer PMNLs will need to be recruited which one would anticipate to result in less tissue damage and lower milk production losses. Still, in this study, oral supplementation of MCFA throughout the dry period and in the first months after calving did neither substantially affect the likelihood of IMI in early lactation nor the composite milk SCC and test-day MY throughout the first 4 months after calving. One MCFA-supplemented cow even suffered from a very severe case of clinical mastitis $5 \mathrm{~d}$ before calving. No antimicrobial activity in vivo of the oral MCFA supplementation was expected as Grummer \& Socha (1989) only found negligible changes in the milk fat composition after oral supplementation of medium chain triglycerides in dairy cows. As MCFA are directly absorbed via the hepatic portal vein, the efficiency of transfer of absorbed MCFA to milk was expected to be low due to extensive oxidation in the liver (Bach \& Barbayan, 1982). The discrepancy between the positive effect of MCFA supplementation on \% blood and milk PMNL apoptosis and the lack of effect on the likelihood for IMI and test-day SCC might be explained by the fact that the risk for IMI and thus an increased SCC is still determined by a balance between the number of bacteria the cow is exposed to and the cow's immune response. Although the role of the cow's immune response might not be underestimated, the number of bacteria the cow is exposed to is most likely still of overriding importance in the establishment of IMI. If cows are exposed to a high number of pathogenic bacteria, there is a very high chance that they will contract an IMI and thus suffer from an increased testday SCC, independently from their immune status. Farms with a BMSCC $>250000$ cell $/ \mathrm{ml}$ probably have less optimal hygienic conditions, thereby maintaining a high level of bacteria in the environment (Barkema et al. 1999). The high number of bacteria the cows were exposed to during the dry period and thereafter might, hypothetically, have outweighed the positive effect of a lower proportion of apoptotic PMNL in the supplemented group compared with the control group on the susceptibility for new IMI in this study. On the other hand, there is increasing evidence from human medicine that MCFA might stimulate the PMNL in a way that they are already exhausted at the time they have contact with pathogens (i.e. probably due to phagocytosis of fat particles) which might, in turn, result in an impaired cellular immune response and hence in a potentially increased risk for either IMI or a more severe inflammatory reaction (Bellinati-Pires et al. 1993; Versleijen et al. 2005). Although no overall effect on the test-day MY was observed and that the supplemented animals had a somewhat higher test-day SCC than the control ones, test-day MY tended to be higher in the supplemented multiparous cows than in their control counterparts at second test-day. Still, evaluation of the oral supplementation of MCFA on the test-day SCC and MY throughout lactation was not the main focus of this rather small-scale explorative clinical trial. Until more thorough research on the effect of MCFA-supplementation and cow performance throughout lactation including more animals on farms with different management styles has been conducted, care should be taken in the interpretation of these data and in drawing conclusions herein.

\section{Conclusions}

Oral supplementation of MCFA to heifers and multiparous cows from 6-8 weeks before calving significantly suppressed the physiological drop in blood and milk PMNL viability in the first days after calving in both heifers and older cows. Oral supplementation of MCFA could, therefore, offer an opportunity to stimulate the cellular immunity and support the cows in meeting their everyday challenges, particularly in the critical period around calving. Although the results seem to be very promising, this was only a first explorative and hypothesis generating study on the immunomodulating effect of MCFA in periparturient dairy cows and thus further research is needed to confirm the findings and scrutinise the underlying mechanisms. Also, multiparous cows might benefit from oral MCFA-supplementation during dry period and in the first months thereafter in the form of increased milk productions at peak lactation although a study including more animals is needed to come to better conclusions.

The authors would like to thank Ir. Lydia Bommelé, André Turtelboom and Karel Vermeulen from Biocentrum Agri-Vet for their excellent cooperation and Lars Hulpio from the Mastitis and Milk Quality Research Unit for the excellent technical assistance. This study was financially supported by Nuscience n.v. (Drongen, Belgium). 


\section{References}

Bach AC \& Barbayan VK 1982 Medium-chain triglycerides: an update. American Journal of Clinical Nutrition 36 950-962

Barkema HW, Van der Ploeg JD, Schukken YH, Lam TJGM, Benedictus G \& Brands A 1999 Management style and its association with bulk milk somatic cell count and incidence rate of clinical mastitis. Journal of Dairy Science 82 1655-1663

Bellinati-Pires R, Waitzberg DL, Salgado MM \& Carneiro-Sampaio MMS 1993 Functional alterations of human neutrophils by medium-chain triglyceride emulsions-evaluation of phagocytosis, bacterial killing \& oxidative activity. Journal of Leukocyte Biology 53 404-410

Bernabucci U, Ronchi B, Lacetera N \& Nardone A 2005 Influence of body condition score on relationships between metabolic status and oxidative stress in periparturient dairy cows. Journal of Dairy Science $\mathbf{8 8}$ 2017-2026

Bouwstra RJ, Nielen M, Stegeman JA, Dobbelaar P, Newbold JR, Jansen EHJM \& van Werven T 2010 Vitamin E supplementation during the dry period in dairy cattle. Part I: adverse effect on incidence of mastitis postpartum in a double-blind randomized field trial. Journal of Dairy Science 93 5684-5695

Bradley AJ \& Green MJ 2010 Managing dry cows to optimize udder health part I: understanding mammary gland susceptibility and the importance of the dry period in mastitis epidemiology. Irish Veterinary Journal 63 384-387

Breckenridge WC \& Kuksis A 1967 Molecular weight distributions of milk fat triglycerides from seven species. Journal of Lipid Research 8 473-478

Castillo C, Hernandez J, Bravo A, Lopez-Alonso M, Pereira V \& Benedito JL 2005 Oxidative status during late pregnancy and early lactation in dairy cows. Veterinary Journal 169 286-292

Ceballos A, Sanchez J, Stryhn H, Montgomery JB, Barkema HW \& Wichtel JJ 2009 Meta-analysis of the effect of oral selenium supplementation on milk selenium concentration in cattle. Journal of Dairy Science $\mathbf{9 2}$ 324-342

Dohme F, Machmüller A, Wasserfallen A \& Kreuzer W 2000 Comparative efficiency of various fats rich in medium-chain fatty acids to suppress ruminal methanogenesis as measured with RUSITEC. Canadian Journal of Animal Science $\mathbf{8 0} 473-482$

Dohme F, Machmüller A, Wasserfallen A \& Kreuzer M 2001 Ruminal methanogenesis as influenced by individual fatty acids supplemented to complete ruminant diets. Letters in Applied Microbiology 32 47-51

Guidry AJ, Paape MJ \& Pearson RE 1976 Effects of parturition and lactation on blood and milk cell concentrations, corticosteroids and neutrophil phagocytosis in the cow. American Journal of Veterinary Research 37 1195-1200

Grummer RR \& Socha MT 1989 Milk fatty-acid composition and plasma energy metabolite concentrations in lactating cows fed medium-chain triglycerides. Journal of Dairy Science 72 1996-2001

Henry GE, Momin RA, Nair MG \& Dewitt DL 2002 Antioxidant and cyclooxygenase activities of fatty acids found in food. Journal of Agricultural and Food Chemistry 50 2231-2234

Kehrli ME, Nonnecke BJ \& Roth JA 1989 Alterations in bovine neutrophil function during periparturient period. American Journal of Veterinary Research 50 207-214

Lemieux H, Blier PU \& Tardif J-C 2008 Does membrane fatty acid composition modulate mitochondrial functions and their thermal sensitivity? Comparative Biochemistry and Physiology Part A: Molecular and Integrative Physiology 149 20-29

Lemieux H, Bulteau AL, Friguet B, Tardif J-C \& Blier PU 2011 Dietary fatty acids and oxidative stress in the heart mitochondria. Mitochondrion 11 97-103

Mehrzad J, Dosogne H, Meyer E, Heyneman R \& Burvenich C 2001 Respiratory burst activity of blood and milk neutrophils in dairy cows during different stages of lactation. Journal of Dairy Research 68 399-415

Mehrzad J, Duchateau L, Pyörälä S \& Burvenich C 2002 Blood and milk neutrophil chemiluminescence and viability in primiparous and pluriparous dairy cows during late pregnancy, around parturition and early lactation. Journal of Dairy Science 85 3268-3276
Mehrzad J, Duchateau L \& Burvenich C 2004 Viability of milk neutrophils and severity of bovine coliform mastitis. Journal of Dairy Science $\mathbf{8 7}$ 4150-4162

Mehrzad J, Duchateau L \& Burvenich C 2005 High milk neutrophil chemiluminescence limits the severity of bovine coliform mastitis. Veterinary Research 36 101-116

Nair MKM, Joy J, Vasudevan P, Hinckley L, Hoagland TA \& Venkitanarayanan KS 2005 Antibacterial effect of caprylic acid and monocaprylin on major bacterial mastitis pathogens. Journal of Dairy Science 88 3488-3495

Paape MJ, Bannerman DD, Zhao X \& Lee JW 2003 The bovine neutrophil: structure and function in blood and milk. Veterinary Research $\mathbf{3 4}$ $597-627$

Pantoja JCF, Hulland C \& Ruegg PL 2009 Somatic cell count across the dry period as a risk factor for the development of clinical mastitis in the subsequent lactation. Journal of Dairy Science 92 139-148

Piepers S, De Meulemeester L, de Kruif A, Opsomer G, Barkema HW \& De Vliegher S 2007 Prevalence and distribution of mastitis pathogens in subclinically infected dairy cows in Flanders, Belgium. Journal of Dairy Research 74 478-483

Piepers S, De Vliegher S, Demeyere K, Lambrecht BN, de Kruif A, Meyer E \& Opsomer G 2009a Technical Note: Flow cytometric identification of bovine milk neutrophils and simultaneous quantification of their viability. Journal of Dairy Science 92 626-631

Piepers S, Opsomer G, Meyer E, Demeyere K, Barkema HW, de Kruif A \& De Vliegher S 2009b Heifer and quarter characteristics associated with periparturient blood and milk neutrophil apoptosis in healthy heifers and in heifers with subclinical mastitis. Journal of Dairy Science 92 4330-4339

Schukken YH, Erb HN, Sears PM \& Smith RD 1988 Ecologic study of the risk factors for environmental mastitis in cows. American Journal of Veterinary Research 49 766-769

Smith KL, Todhunter DA \& Schoenberger PS 1985 Environmental pathogens and intramammary infection during dry period. Journal of Dairy Science $68402-417$

Sordillo LM \& Aitken SL 2009 Impact of oxidative stress on the health and immune function of dairy cattle. Veterinary Immunology and Immunopathology 128 104-109

Van Oostveldt K, Dosogne H, Burvenich C, Paape MJ, Brochez V \& Van den Eeckhout E 1999a Flow cytometric procedure to detect apoptosis of bovine polymorphonuclear leukocytes in blood. Veterinary Immunology and Immunopathology $\mathbf{7 0}$ 125-133

Van Oostveldt K, Burvenich C, Paape MJ \& Meyer E 1999b The effect of diapedesis on the apoptotic response of isolated bovine neutrophils. Cell Biology International 23 755-791

Van Oostveldt K, Vangroenweghe F, Dosogne H \& Burvenich C 2001 Apoptosis and necrosis of blood and milk polymorphonuclear leukocytes in early and midlactating healthy cows. Veterinary Research 32 617-622

Van Oostveldt K, Paape MJ, Dosogne H \& Burvenich C 2002 Effect of apoptosis on phagocytosis, respiratory burst and CD 18 adhesion receptor expression of bovine neutrophils. Domestic Animal Endocrinology 22 37-50

Vermes I, Clemens H, Steffens-Nakken H \& Reutelingsperger C 1995 A novel assay for apoptotis flow cytometric detection of phosphatidylserine expression on early apoptotic cells using fluorescein labelled Annexin V. Journal of Immunological Methods 184 39-51

Versleijen M, Roelofs H, Preijers F, Roos D \& Wanten G 2005 Parenteral lipids modulate leukocyte phenotypes in whole blood, depending on their fatty acid composition. Clinical Nutrition $\mathbf{2 4}$ 822-829

Versleijen MWJ, van Esterik JCJ, Roelofs HMJ, van Ernst-de Vries SE, Willems PHGM \& Wanten GJA 2009 Parenteral medium-chain triglyceride-induced neutrophil activation is not mediated by a Pertussis toxin sensitive receptor. Clinical Nutrition 28 59-64

Wanten GJA, Janssen FP \& Naber AHJ 2002 Saturated triglycerides and fatty acids activate neutrophils depending on carbon chain-length. European Journal of Clinical Investigation 32 285-289 